\title{
Anti-Hypertensive Prescription and Cost Patterns in an Outpatient Department of a Teaching Hospital in Lagos State Nigeria
}

\author{
Akin Osibogun, Tochi Joy Okwor* \\ Department of Community Medicine, Lagos University Teaching Hospital, Lagos, Nigeria \\ Email: okwortochi@yahoo.com
}

Received 17 January 2014; revised 8 March 2014; accepted 18 March 2014

Copyright (C) 2014 by authors and Scientific Research Publishing Inc. This work is licensed under the Creative Commons Attribution International License (CC BY). http://creativecommons.org/licenses/by/4.0/

(c) (i) Open Access

\begin{abstract}
Introduction: Hypertension is a public health problem with a high prevalence in Nigeria. The cost of prescription medications is thought to be a barrier for many patients to access the healthcare they need. This study was aimed at identifying associated co-morbid conditions, the prescribing patterns and cost of prescription for the treatment of hypertension in an outpatient clinic at Lagos University Teaching Hospital. Materials and Methods: A cross sectional study was carried out. A total of 147 prescriptions were obtained from the case notes of patients treated at the LUTH outpatient department between February 2012 and August 2012. For each prescription, the number of drugs, the class and combinations of antihypertensives were recorded. The monthly cost of a 30-day anti-hypertensive supply based on the recommended daily dose was calculated. Results: The mean age of the patients was $54(+/-14)$ years and of the 147 prescriptions, $77(52.4 \%)$ was for females and $70(47.6 \%)$ was for males. The mean systolic blood pressure was $141.6 \mathrm{mmHg}$ $(+/-20.5 S D)$ and mean diastolic blood pressure was $86.5 \mathrm{mmHg}(+/-13.3 \mathrm{SD})$. Of the 147 prescriptions, $112(76.2 \%)$ were for patients with co-morbidities. The frequency of prescription of the various classes of anti hypertensives are; diuretics $117(79.6 \%)$, angiotensin receptor blockers 78(53.1\%), angiotensin converting enzyme inhibitors 65(44.2\%), calcium channel blockers 65 (44.2\%) beta blockers $54(36.7 \%)$ and centrally acting agents 12(8.2\%). Average cost per month was $=\mathrm{N}=6611.47$ (US\$44). There was a statistically significant association between co morbid conditions and high cost of prescriptions with $73.7 \%$ of those with diabetes and $63.2 \%$ of those with renal disease having cost of prescriptions within the high cost group $(p<0.05)$. Conclusion: The cost per month is high and it is recommended that hypertension should be addressed as part of an integrated care program. Ingenious ways of health care financing also have to be promoted.
\end{abstract}

"Corresponding author.

How to cite this paper: Osibogun, A. and Okwor, T.J. (2014) Anti-Hypertensive Prescription and Cost Patterns in an Outpatient Department of a Teaching Hospital in Lagos State Nigeria. Open Journal of Preventive Medicine, 4, $156-163$. http://dx.doi.org/10.4236/ojpm.2014.44021 


\section{Keywords}

\section{Hypertension; Prescription Patterns; Co-Morbidity; Cost; Nigeria}

\section{Introduction}

Hypertension is a public health problem and in the year 2000 hypertension was estimated to affect almost one billion patients worldwide and the prevalence is predicted to increase by approximately $60 \%$ by 2025 representing an increase from $26.4 \%$ in 2000 to $29.2 \%$ in 2025 worldwide [1]. In Nigeria, there is a high incidence of hypertension and hypertension-associated diseases with a consequent heavy burden on the public healthcare system. Africa has the highest prevalence of hypertension in the world as $46 \%$ of adults aged 25 years and above has a raised blood pressure [2] and a study in eastern Nigeria found a prevalence of $40.3 \%$ among the males [3] [4].

Uncontrolled hypertension leads to severe long-term consequences such as stroke, heart failure, coronary heart disease and end-stage kidney disease. It is also associated with diabetes mellitus. Hypertension related deaths constitute one third of global mortality cases and there is scientific evidence to suggest that such adverse outcomes can be prevented by lowering blood pressure effectively [5]. It is therefore important that once hypertension is diagnosed, a rational anti-hypertensive therapy on a long term basis along with regular follow up is instituted.

In addition to the large health burden, there is also an enormous financial burden associated with the disease [6]. Hypertension has been estimated to cost about $4.5 \%$ of the global disease burden [1]. This is because the treatment of hypertension requires an investment over many years to ensure disease-free years among those affected. The economic consequences of this long term therapy often limit the ideals of pharmacologic blood pressure control in many developing countries including Nigeria.

The per capita income in Nigeria as at 2012 was $\$ 2700.00$ (two thousand seven hundred US Dollars). Also the minimum wage is $=\mathrm{N}=18000.000$ (eighteen thousand Naira equivalent of US\$120.00 (one hundred and twenty US Dollars at an exchange rate of $=\mathrm{N}=150$ to the Dollar)). These figures are low and if a big percentage of this monthly income is spent on buying medicines for the management of hypertension, it leaves a very little amount for other things. The implication of this may be that patients may prioritize their spending and forego the purchase of the medications in order to buy food and other essential supplies for the family. The cost of prescription medications is thought to be a barrier for many patients to access the healthcare they need. Cost-related non adherence (CRN) is defined as any form of medication under use because of cost, including unfilled prescriptions, delayed prescriptions, smaller doses and less frequent doses [7].

A study conducted in a rural community in Ibadan South West Nigeria found that the economic burden of hypertension treatment was significant and that about half of the patients were spending a tenth or more of their income on health care related expenses [8]. In addition to the direct costs in the form of amount paid for the prescribed drugs, there are also indirect costs related to lost man hours and savings due to catastrophic healthcare expenditures. The situation in Nigeria is such that healthcare financing is mainly out of pocket payments and often the burden is borne entirely by the individuals affected [9]. Given the growth in healthcare expenditure and the limited resources for healthcare, there is a clear need to explore prescription patterns and trends, in a chronic disease such as hypertension [10].

The primary goal of anti-hypertensive therapy is to prevent morbidity and mortality associated with hypertension. Many studies have demonstrated that lifestyle modifications and adherence to appropriate drug treatments are sufficient to maintain blood pressure at optimal levels [11]. Various drug classes are used in the management of hypertension and they include diuretics (D), $\beta$-blockers (BB), calcium channel blockers (CCB), angiotensin converting enzyme (ACE) inhibitors and angiotensin II receptor blockers (ARB). According to Joint National Committee on the Prevention, Detection, Evaluation and Treatment of High Blood Pressure (JNC), WHO/ISH and ESH guidelines, effective drug combinations include; 1) D and BB; 2) D and ACEI/ARB; 3) CCB and BB; 4) CCB and ACEI or ARB; 5) CCB and D; 6) alpha-blocker and BB; 7) Other combinations (that may include centrally acting agents, including alpha 2-adrenoceptor agonist and imidazoline-I2 receptor modulators, or ACEIs or ARBs) can be used, if necessary. If a single drug does not adequately control blood pressure, drugs 
with different modes of action can be combined to effectively lower blood pressure while minimizing toxicity (stepped care). In many cases, 3 or 4 drugs may be necessary.

The presence of co-morbid conditions also influences selection of anti-hypertensive drugs because two diseases may be treated with a single drug. Co-morbidities are diseases or disorders that coexist with a disease of interest. Co-morbid illnesses are important because they may delay diagnosis, may influence treatment decisions, are related to complications, alter survival, and confound analysis [12].

This study was aimed at identifying the patient parameters, associated co-morbid conditions, the prescribing patterns and cost of prescription for the treatment of hypertension in an outpatient clinic at Lagos University Teaching Hospital (LUTH) Idi Araba, Lagos State Nigeria.

\section{Materials and Methods}

This cross sectional study was carried out at Lagos University Teaching Hospital (LUTH) Idi Araba, Lagos. The first step was to retrieve the case notes of patients that attended the cardiology out-patients' clinic between February 2012 and August 2012, from the Health Records Department of the hospital. According to the World Health Organization document on how to investigate drug use in Health facilities, a minimum of 100 prescriptions per clinic is expected to give a $95 \%$ confidence interval of within $10 \%$ for the individual result [13].

A total of 147 prescriptions were obtained from the case notes examined. The following information was retrieved; age, gender, occupation, and the pattern of prescribed drugs for hypertension. For each prescription, the number of drugs, the class and combinations of anti-hypertensives, the number of generics and brands, and cost per month were recorded. The prices of the drugs were obtained from the LUTH hospital pharmacy.

Multitherapy was defined as two or more drug combinations from different anti-hypertensive drug classes while monotherapy was defined as the use of a single medication containing only one anti-hypertensive agent. The pattern of drug combination was also examined. Subjects with co-morbidities were noted and the number of co-morbid conditions was reported.

Cost examined was the cost of all the medications on the prescription. Cost was calculated as a function of the dosage prescribed and the prices in the hospital pharmacy. The monthly cost of a 30-day anti-hypertensive supply based on the recommended daily dose was calculated.

The data entry and analysis was carried out using the IBM SPSS version 20 on a personal computer. Categorical data are presented as proportions and percentages while continuous variables are expressed as means (+/- standard deviation). A p value of $<0.05$ is considered as significant.

Ethical approval was sought and obtained from the LUTH Ethical Committee.

\section{Results}

\section{Socio-Demographic Characteristics (Patient Parameters)}

The mean age of the patients was 54(+/-14) years. Of the 147 prescriptions, 77(52.4\%) was for females and 70(47.6\%) was for males (Table 1 ).

The mean systolic blood pressure was $141.6 \mathrm{mmHg}(+/-20.5 \mathrm{SD})$ and mean diastolic blood pressure was 86.5 mmHg (+/-13.3SD).

Out of the 147 prescriptions, 112(76.2\%) were for patients with co-morbidities. In looking at the association between co-morbidity and cost of prescription per month, it was found that the highest proportion of prescriptions for patients with co-morbidity was in the high cost per month group this was significant $(p<0.05)$ (Table 2).

The anti hypertensives prescribed belonged to the following classes; diuretics, angiotensin receptor blockers, angiotensin converting enzyme inhibitors, calcium channel blockers, beta receptor blockers and centrally acting agents. Almost all the prescriptions (146, 99.3\%) had more than one anti-hypertensive (that is multitherapy). The frequency of prescription of the various classes of anti hypertensives were; diuretics 117(79.6\%), angiotensin receptor blockers 78(53.1\%), angiotensin converting enzyme inhibitors 65(44.2\%), calcium channel blockers $65(44.2 \%)$ beta blockers 54(36.7\%) and centrally acting agents $12(8.2 \%)$. Seventy one (48.3\%) of the prescriptions had 3 or more generic names while only 32(21\%) had brand names on them (Table 3).

The commonest combination prescribed was the angiotensin receptor blocker/diuretic combination which represented $16 \%$ followed by the triple combination of angiotensin converting enzyme inhibitor/beta blocker 
Table 1. Socio-demographic characteristics.

\begin{tabular}{cc}
\hline Variable & Frequency (\%) N = 147 \\
\hline Age (years) & $15(10.2 \%)$ \\
$25-35$ & $38(25.9 \%)$ \\
$36-45$ & $18(12.2 \%)$ \\
$46-55$ & $36(24.5 \%)$ \\
$56-65$ & $40(27.2 \%)$ \\
$>65$ & \\
Sex & $70(47.6 \%)$ \\
Male & $77(52.4 \%)$ \\
Female & \\
Marital status & $94(63.9 \%)$ \\
Married & $19(12.9 \%)$ \\
Single & $34(23.1 \%)$ \\
Widowed &
\end{tabular}

Table 2. Clinical profile of patients.

\begin{tabular}{|c|c|}
\hline \multicolumn{2}{|c|}{ Variable Frequency (\%) } \\
\hline \multicolumn{2}{|c|}{ Systolic BP (mmHg) } \\
\hline $90-120$ & 28(19) \\
\hline $121-139$ & $40(27.2)$ \\
\hline $140-159$ & 49 (33.3) \\
\hline$>160$ & $30(20.4)$ \\
\hline \multicolumn{2}{|l|}{ Diastolic BP } \\
\hline $60-79$ & $30(20.4)$ \\
\hline $80-89$ & $46(31.3)$ \\
\hline $90-99$ & $37(25.2)$ \\
\hline $100-140$ & $34(23.1)$ \\
\hline \multicolumn{2}{|c|}{ Co-morbidity } \\
\hline Yes & $112(76.2 \%)$ \\
\hline No & $35(23.8 \%)$ \\
\hline \multicolumn{2}{|c|}{ Co-morbidities } \\
\hline Diabetes & $19(12.9 \%)$ \\
\hline Stroke & $5(3.4 \%)$ \\
\hline Heart disease & $34(23.1 \%)$ \\
\hline Renal disease & $19(12.9 \%)$ \\
\hline Dyslipideamia & $34(23.1 \%)$ \\
\hline
\end{tabular}


Table 3. Patterns of anti-hypertensive prescription.

\begin{tabular}{cc}
\hline Variable & Frequency (\%) \\
\hline \multicolumn{1}{c}{ No of medications } & \\
Monotherapy & $6(4.1 \%)$ \\
Multitherapy & $141(95.9 \%)$ \\
ACEI & \\
ARBS & $66(44.9 \%)$ \\
Beta blockers & $78(53.1 \%)$ \\
CCBs & $54(36.7 \%)$ \\
Diuretics & $66(44.9 \%)$ \\
Centrally acting agents & $117(79.6 \%)$ \\
Drug combination & $12(8.2 \%)$ \\
\hline ARB + D & Frequency (\%) \\
ACEI + BETA B + D & $24(16)$ \\
ACEI + CCB + D & $19(12.9)$ \\
ARB + CCB + & $16(10.9)$ \\
ARB + BETA B + D & $16(10.9)$ \\
ARB + CCB + D & $12(8.2)$ \\
\hline ACE + D & $11(7.5)$ \\
\hline BETA B + CCB + D & $8(5.4)$ \\
\hline & $8(5.4)$ \\
\hline & $6(4.1)$ \\
\hline & $5(3.4)$ \\
\hline
\end{tabular}

and diuretic. The least prescribed combination was the angiotensin receptor blocker/beta blocker/calcium channel blocker and diuretic combination.

The mean and monthly costs of the prescriptions were $=\mathrm{N}=6611.47$ (six thousand six hundred and eleven Naira) and $=\mathrm{N}=5917.00$ (five thousand nine hundred and seventeen Naira) respectively. The lowest cost per month was $=\mathrm{N}=300.00$ (three hundred Naira) while the highest cost per month was $=\mathrm{N}=27030.00$ (twenty seven thousand thirty Naira) (Table 4).

\section{Discussion}

It was observed that there were a higher number of women than men encountered over the study period. Some researchers have expressed the view that this is either because males do not regularly keep clinic appointments, or that it is a reflection of poorer awareness of blood pressure status among the males [14] [15].

Almost all the prescriptions were multi therapy as shown by the $95.9 \%$ representing 141 prescriptions. The use of multitherapy is encouraged by JNC WHO/ISH and ESH guidelines, which states that small doses of different classes of anti-hypertensive drug is more beneficial than a high dose of one [15] [16].

The finding in this study that diuretics was the most commonly prescribed drug among this group is in line with the findings of a study done in Ibadan, Nigeria where thiazide diuretic was the most commonly prescribed anti-hypertensive [17]. This finding also reflects the usefulness of diuretics in patients in this environment. According to the ESH guidelines, thiazides diuretics are useful in elderly patients, those with congestive heart failure and hypertensives of African origin. The higher prevalence of women in this study, mean age of the population and race, are factors that favour the use of diuretics in achieving BP control in the study population. The top 
Table 4. Cost pattern.

\begin{tabular}{cc}
\hline Variable & Frequency $(+/-\mathrm{SD})=\mathrm{N}=$ \\
\hline Mean monthly cost per prescription & $6611.47(5157.71)$ \\
Lowest cost per month & 300.00 \\
Highest cost per month & 27030.00 \\
Median cost per month & 5917.00 \\
\hline Variable & Frequency (\%) N =147 \\
\hline Level of cost per month in $=\mathrm{N}=$ & $48(32.7 \%)$ \\
$300-3000$ (low) & $39(26.5 \%)$ \\
3001 - 7000 (medium) & $60(40.8 \%)$ \\
\hline 7000 (High) &
\end{tabular}

five combinations of anti-hypertensives in this study indicate a very close adherence to the JNC 2003 guidelines. The physicians in this tertiary institution have adhered to these guidelines and this may be a reflection of the quality of training received by the physicians.

The mean monthly cost of prescription in this group studied was $=\mathrm{N}=6611.47$ (equivalent of $\$ 44.00$ USD) representing $36.7 \%$ of the minimum wage in Nigeria. This is a high percentage of income to spend on medicines. The per capita income in Nigeria as at 2012 was \$2700.00 (two thousand seven hundred US Dollars). Also the minimum wage is $=\mathrm{N}=18000.000$ (eighteen thousand Naira equivalent of $\$ 120.00$ (one hundred and twenty US Dollars at an exchange rate of $=\mathrm{N}=150$ to the Dollar)). These figures are low and if a big percentage of this monthly income is spent on buying medicines for the management of hypertension, it leaves a very little amount for other things. The implication of this may be that patients may prioritize their spending and forego the purchase of the medications in order to buy food and other essential supplies for the family.

The cost of prescription medications is thought to be a barrier for many patients to access the healthcare they need. Cost-related non adherence (CRN) is defined as any form of medication under use because of cost, including unfilled prescriptions, delayed prescriptions, smaller doses and less frequent doses [7].

A study conducted in a rural community in Ibadan South West Nigeria found that the economic burden of hypertension treatment was significant and that about half of the patients were spending a tenth or more of their income on health care related expenses [8]. The present study shows that over $30 \%$ of the minimum wage is spent per month. In addition to the direct costs in the form of amount paid for the prescribed drugs, there are also indirect costs related to lost man hours and savings due to catastrophic healthcare expenditures. The situation in Nigeria is such that healthcare financing is mainly out of pocket payments and often the burden is borne entirely by the individuals affected [9].

The prevalence of co-morbidities was high among those studied with 147 of the prescriptions, $112(76.2 \%)$ being for patients with co-morbidities. In looking at the association between co-morbidity and cost of prescription per month, it was found that the highest proportion of prescriptions for patients with co-morbidity was in the high cost per month group (over $=\mathrm{N}=7000.00$ per month) this was significant $(\mathrm{p}<0.05)$ (Table 5). A study in a rural community in Ibadan also found that the mean total cost of treatment was significantly higher for those with co-morbidity [17]. This implies that patients with co-morbidities spend significantly more per prescription compared to their counterparts without co-morbidities. It also makes a case for more emphasis on lifestyle modifications for all patients and a stricter monitoring of blood pressure control in such patients. The patient with hypertension and certain co-morbidities requires special attention and follow up by the clinician. The cost of medications and the complexity of care (i.e., transportation, patient difficulty with polypharmacy, difficulty in scheduling appointments, and life's competing demands) are additional barriers that must be overcome to achieve blood pressure goals [11].

The high costs observed in this study also make a strong case for further strengthening of the health insurance system in Nigeria to enable patients get the appropriate treatment they need without being thrown into financial crisis. It is also recommended that in order to prevent complications of hypertension which is a critical element 
Table 5. Association between co-morbidities and cost per month $\mathrm{N}=112$.

\begin{tabular}{|c|c|c|c|c|c|}
\hline \multirow{2}{*}{ Variable } & \multicolumn{3}{|c|}{ Cost per month } & \multirow{2}{*}{ Fischer's exact test } & \multirow{2}{*}{ p-value } \\
\hline & Low & Medium & High & & \\
\hline \multicolumn{6}{|c|}{ Cormobidity } \\
\hline Yes & $40(35.7 \%)$ & $16(14.3 \%)$ & $56(50 \%)$ & \multirow[b]{2}{*}{34.94} & \multirow[b]{2}{*}{$<0.001^{* * *}$} \\
\hline No & $8(22.9 \%)$ & $23(65.7 \%)$ & $4(11.4 \%)$ & & \\
\hline \multicolumn{6}{|l|}{ Diabetes } \\
\hline Yes & $3(15.8 \%)$ & $2(10.5 \%)$ & $14(73.7 \%)$ & \multirow{2}{*}{8.879} & \multirow{2}{*}{$0.012^{* *}$} \\
\hline No & $45(32.5 \%)$ & $37(28.9 \%)$ & $46(35.9 \%$ & & \\
\hline \multicolumn{6}{|c|}{ Heart disease } \\
\hline Yes & $22(64.7 \%)$ & $3(8.8 \%)$ & $9(26.5 \%)$ & \multirow{2}{*}{20.082} & \multirow{2}{*}{$<0.001^{* *}$} \\
\hline No & $26(23.0 \%)$ & $36(31.9 \%)$ & $51(45.1 \%)$ & & \\
\hline \multicolumn{6}{|c|}{ Renal disease } \\
\hline Yes & $6(31.6 \%)$ & $1(5.3 \%)$ & $12(63.2 \%)$ & \multirow{2}{*}{6.673} & \multirow{2}{*}{$0.030^{* *}$} \\
\hline No & $42(32.8 \%)$ & $38(29.7 \%)$ & $48(37.5 \%)$ & & \\
\hline \multicolumn{6}{|c|}{ Dyslipideamia } \\
\hline Yes & $8(23.5 \%)$ & $9(26.5 \%)$ & $17(50.0 \%)$ & \multirow{2}{*}{2.018} & \multirow{2}{*}{0.359} \\
\hline No & $40(35.4 \%)$ & $30(26.5 \%)$ & $43(38.1 \%)$ & & \\
\hline
\end{tabular}

${ }^{* *} \mathrm{p}<0.05$.

of containing cost, hypertension should be addressed as a part of integrated primary care program as proposed by the World Health Organization [2]. The cost of implementing such a program has been estimated at about one US Dollar (US\$1) per head in low-income countries such as Nigeria.

A limitation to this study is that data was collected from health records. This limits the amount of information that can be collected and the ability to explore other areas such as patient's perception of impact of the cost on their compliance.

\section{Conclusions}

The pattern of antihypertensive prescription at the LUTH outpatient department is in close compliance to the JNC WHO/ISH and ESH guidelines. There is however a high prevalence of co morbid conditions mostly heart disease and dyslipideamia.

While there is a close compliance to the JNC WHO/ISH and ESH guidelines, the cost per month is high relative to the Nation's per capita income and minimum wage levels. An integrated primary care approach should be adopted in the control of hypertension and also, ingenious ways of health care financing such as community based health care financing and other social health insurance schemes have to be promoted to enable people to pay for these health care costs.

\section{References}

[1] Kearny, P.M., Whelton, M., Reynolds, K., Muntner, P., Whelton, P.K. and He, J. (2005) Global Burden of Hypertension: Analysis of Worldwide Data. Lancet, 365, 217-223. http://dx.doi.org/10.1016/S0140-6736(05)17741-1

[2] World Health Organization (2013) A Global Brief on Hypertension; Silent Killer, Global Public Health Crisis. World Health Organization, Geneva.

[3] Ekwunife, O.I., Udeogaranya, P.O. and Nwatu, I.L. (2010) Prevalence, Awareness, Treatment and Control of Hypertension in a Nigerian population. Health, 2, 731-735. http://dx.doi.org/10.4236/health.2010.27111 
[4] Erhun, W.O., Olayiwola, G., Agbani, E.O. and Omotosho, N.S. (2005) Prevalence of Hypertension in a University Community in South West Nigeria. African Journal of Microbiology Research, 8, 15-19.

[5] Neal, B., MacMahon, S. and Chapman, N. (2000) The Blood Pressure Lowering Treatment Trialists Collaboration. Effects of ACE Inhibitors, Calcium Antagonists, and Other Blood-Pressure-Lowering Drugs: Results of Prospectively designed Overview of Randomized Trials. Lancet, 355, 1955-1964.

[6] Amira, C.O. and Okubadejo, N.U. (2006) Antihypertensive Pharmacotherapy in a Developing Economy: Pattern, Acquisition Costs and Conformity to International Guidelines in a Tertiary-Care Setting. Journal of Human Hypertension, 20, 894-897. http://dx.doi.org/10.1038/sj.jhh.1002080

[7] Zheng, B., Poulose, A.F. and Holbrook, A. (2012) A Pilot Study on Cost-Related Medication Non Adherence in Ontario. Journal of Population Therapeutics and Clinical Pharmacology, 19, 239-47.

[8] Ilesanmi, O.S., Ige, O.K. and Adebiyi, A.O. (2012) The Managed Hypertensive: The Cost of Blood Pressure Control in a Nigerian Town. The Pan African Medical Journal, 12, 96.

[9] Obikeze, O.O., Ige, O.K., Osungbade, K.O., Olumide, E.A. and Asuzu, M.C. (2010) An Overview of the National Health Insurance Scheme in Nigeria. Dokita, 1, 15-21.

[10] Liu, P.-H. and Wang, J.-D. (2008) Antihypertensive Medication Prescription Patterns and Time Trends for Newly Diagnosed Uncomplicated Hypertension Patients in Taiwan. BMC Health Services Research, 8.

[11] US Department of Health and Human Services, National Institutes of Health, National Heart LaBI (2003) The Seventh Report of the Joint National Committee on Prevention, Detection, Evaluation and Treatment of High Blood Pressure. NIH Report No. 03-5233.

[12] Hall, S.H. (2006) A User's Guide to Selecting a Comorbidity Index for Clinical Research. Journal of Clinical Epidemiology, 59, 849-855. http://dx.doi.org/10.1016/j.jclinepi.2005.11.013

[13] Hogerzeil, H.V., Ross-Degnam, D., Laing, R.O., Ofori, A., Santoso, B., Azad, C.A.K., et al. (1993) Field Tests for Rational Drug Use in Developing Countries. Lancet, 324, 1408-1410. http://dx.doi.org/10.1016/0140-6736(93)92760-Q

[14] Adebisi, S.A., Oghagbon, E.K. and Jimoh, A.K. (2003) Glycated Haemoglobin and Associated Variables in Diabetics: Ilorin Experience. West African Journal of Medicine, 22, 318-320.

[15] Odili, V.U., Oghagbon, E.K., Ugwa, N.A., Ochei, U.M. and Aghomo, O.E. (2008) Adherence to International Guidelines in the Management of Hypertension in a Tertiary Hospital in Nigeria. Tropical Journal of Phatmaceutical Research, 7, 945-952. http://dx.doi.org/10.4314/tjpr.v7i2.14608

[16] Ma, J., Lee, K. and Stafford, R.S. (2006) Changes in Antihypertensive Prescribing during US Outpatient Visits for Uncomplicated Hypertension between 1993 and 2004. Hypertension, 48, 846-852. http://dx.doi.org/10.1161/01.HYP.0000240931.90917.0c

[17] Adigun, A.Q., Ishola, D.A., Akintomide, A.O. and Ajayi, A.A. (2003) Shifting Trends in the Pharmacological Treatment of Hypertension in a Nigerian Tertiary Hospital: A Real World Evaluation of the Efficacy, Safety, Rationality and Pharmacoeconomics of Old and New Antihypertensive Drugs. Journal of Human Hypertension, 17, 277-285. http://dx.doi.org/10.1038/sj.jhh.1001538 